\title{
EFFECT OF GAMMA IRRADIATION ON CHLOROPHYLL CONTENT IN THE COWPEA (VIGNA UNGUICULATA (L.) WALP)
}

\author{
C. Azigwe, P. A. D. Zoryeku, I. K. Asante * And F. Oppong-Adjei \\ (Department of Plant and Environmental Biology, University of Ghana, Legon). \\ *Corresponding author's email: asanteisaack57@gmail.com
}

\begin{abstract}
The experiment was conducted to study the mutagenic effect of gamma rays on chlorophyll content at three different physiological stages in the cowpea: pre-flowering, flowering and post-flowering. Five sets of cowpea seeds were subjected to individual doses of gamma rays: $400 \mathrm{~Gy}, 450 \mathrm{~Gy}, 500 \mathrm{~Gy}, 600 \mathrm{~Gy}$ and $0 \mathrm{~Gy}$. The seeds were sown to raise the $\mathrm{M}_{1}$ generation. The $M_{1}$ generation seeds were collected and sown in the next season to raise the $M_{2}$ generation. Leaf chlorophyll content was measured for $\mathrm{M}_{2}$ generation plants. Mean chlorophyll content for pre-flowering stage ranged between $38.9 \pm 8.17$ (control) and $64.2 \pm 6.16$ (400 Gy). Flowering stage mean chlorophyll content ranged from $48.3 \pm 14.4$ (600 Gy) to $99.4 \pm 6.22$ (450 Gy). Post-harvest chlorophyll mean content ranged between $13.1 \pm 0.98$ (600 Gy) and $38.0 \pm 1.90$ (400 Gy). There were significant differences in treatment effects for pre-flowering $(\mathrm{P}=0.021)$, flowering $(\mathrm{P}=0.005)$ and harvest $(\mathrm{P}=0.000)$. At pre-flowering treatment, treatment $400 \mathrm{~Gy}$ scored a significant increase of 64 percent $(\mathrm{P}=0.02)$ above the control. The optimum dose for useful induced mutation for increases in chlorophyll concentration in the cowpea was $400 \mathrm{~Gy}$.
\end{abstract}

Keywords: gamma irradiation, chlorophyll content, pre-flowering, flowering, post-flowering

\section{Introduction}

Gamma rays can induce different types of variations more than any other radiation (Patil and Rane, 2015). They have been found to be effective in inducing chlorophyll mutations. Some of the variations observed after mutagenesis include chlorophyll mutations and morphological changes.

Chlorophyll development appears to be under the control of many genes which are located on several chromosomes (Swaminathan et al., 1962). Effect of gamma rays may therefore cause nuclear gene mutations or chromosomal mutations which might result in chlorophyll deficient mutations. Chlorophyll mutations seem to be the most dependable indices for evaluating the efficiency of different mutagen in inducing genetic variability.

Chlorophyll is an important pigment to plants because the light energy it absorbs is used to manufacture food during photosynthesis. The level of tolerance to mutation by plants can be checked by calculating chlorophyll content and chlorophyll mutations. It has been reported by several authors that chlorophyll content decreases with increasing doses/ concentrations of mutagens (Rahimzadeh et al., 2011; Verma et al., 2010).

Cowpea is one of the ancient crops known to man (Meiya, 2004) and one of the first human food sources since Neolithic times (Agyeman et al, 2014). It belongs to family Fabaceae and has a diploid chromosome 
number 22 (i.e., $2 \mathrm{n}=22$ ). Cowpea is grown in 16 African countries with the continent producing two-thirds of the world total (Agyeman et al, 2014). West Africa produces the most diverse cultivated cowpea in an area including the Savanna region of Nigeria, Southern Niger, part of Burkina Faso, Northern Benin, Togo, and the Northwestern part of Cameroon (Doumbia, 2012). The current experiment was conducted to study the mutagenic effect of gamma rays on chlorophyll content at three different physiological stages in the cowpea.

\section{Experimental}

Fresh and viable seeds of one cowpea variety were used for the experiment. Five sets of 100 seeds each were given the following individual doses of gamma rays: 400, 450, 500, 600 and 0 Gy (Gray) was were used for the experiment. Seeds were irradiated through gamma irradiation process of Cobalt 60 at the Radiation Technology Centre of the Ghana Atomic Energy Commission. Seeds were planted at the experimental plot of the Department of Plant and Environmental Biology, University of Ghana Legon in the crop season of 2017-2018 in single row plots. $\mathrm{M}_{1}$ generation seeds were collected and sown in the next cropping season of 2018-2019. $\mathrm{M}_{2}$ generation plants were screened to measure their chlorophyll contents at pre-flowering, flowering and post-flowering stages by using the Chlorophyll content meter (SPAD 502). Readings were taken from the median leaflet of the trifoliate leaf from each plant. SPSS statistical software was used to analyze the data by applying the general linear model. Multivariate test was conducted to test for between subjects' effects. The LSD method was used for multiple comparison of means.

\section{Results and discussion}

Results for pre-flowering, flowering and harvest stages are presented in Table 1. Mean chlorophyll content values for pre-flowering ranged between $38.9 \pm 8.17$ (control) and $64.2 \pm 6.16$ (400 Gy), while those for flowering and post-flowering ranged from $48.3 \pm 14.4$ (600 Gy) to $99.4 \pm 6.22(450 \mathrm{~Gy})$ and $13.1 \pm 0.98$ (600 Gy) to $38.0 \pm 1.90$ (400 Gy), respectively.

TABLE 1

Mean leaf chlorophyll content for three phenological stages at 5 different levels of genome irradiation in cowpea.

\begin{tabular}{cccc}
\hline $\begin{array}{c}\text { Treatment } \\
\text { (Gy) }\end{array}$ & Pre-flowering & $\begin{array}{c}\text { Phenological stage } \\
\text { Flowering }\end{array}$ & Post-flowering \\
\hline Control & $38.9 \pm 8.17$ & $86.6 \pm 6.43$ & $33.7 \pm 3.09$ \\
400 & $64.2 \pm 6.16$ & $98.9 \pm 6.46$ & $38.0 \pm 1.90$ \\
450 & $53.2 \pm 7.00$ & $99.4 \pm 6.22$ & $30.4 \pm 3.79$ \\
500 & $43.7 \pm 3.43$ & $79.0 \pm 5.01$ & $27.6 \pm 1.51$ \\
600 & $44.3 \pm 8.20$ & $48.3 \pm 14.4$ & $13.1 \pm 0.98$ \\
\hline
\end{tabular}

Multivariate test for treatment effect was highly significant by Wilks' Lambda test (values $=0.109, \mathrm{~F}=3.52, \mathrm{P}$ $=0.000$ ). There were significant differences in treatment effects for the various phenological stages as shown in Table 2; the significant levels were as follows: pre-flowering $(\mathrm{P}=0.021)$, flowering $(\mathrm{P}=0.005)$ and post-flowering $(\mathrm{P}=0.000)$. 
TABLE 2

Mean square values for between-treatments effects.

\begin{tabular}{llllll}
\hline Source & Dependent variable & df & Mean square & F & P-value \\
\hline \multirow{4}{*}{ Treatment } & Pre-flowering & 4 & 1898.5 & 3.06 & 0.021 \\
& Flowering & 4 & 2998.2 & 4.00 & 0.005 \\
& Post-flowering & 4 & 702.00 & 7.93 & 0.000 \\
\hline \multirow{2}{*}{ Error } & Pre-flowering & 75 & 619.18 & & \\
& Flowering & 75 & 751.33 & & \\
\hline
\end{tabular}

Multiple comparisons of means by the Least Significant Difference method are presented in Table 3.

TABLE 3

Multiple comparisons of treatment mean for the three phenological stages by the Least Significant Difference method.

\begin{tabular}{llllll}
\hline \multirow{2}{*}{ Treatment } & Phenological stage & Control & 400 & 450 & 500 \\
\hline \multirow{4}{*}{400} & Pre-flowering & $25.3^{*}$ & & & \\
& Flowering & 12.2 & & & \\
& Post-flowering & 4.4 & & & \\
450 & Pre-flowering & 14.2 & 11.1 & & \\
\hline \multirow{4}{*}{500} & Flowering & 12.8 & 0.5 & & \\
& Post-flowering & -3.3 & 7.6 & & \\
& Pre-flowering & $4.7^{*}$ & $20.5^{*}$ & 9.5 & \\
6 & Flowering & -7.6 & $-19.9^{*}$ & -20.4 & \\
& Post-flowering & -6.1 & $10.4^{*}$ & 2.8 & -8.8 \\
& Pre-flowering & 5.4 & 19.9 & 8.8 & \\
& Flowering & $38.3^{*}$ & $50.6^{*}$ & $51.1^{*}$ & $-30.7^{*}$ \\
& Post-flowering & 20.6 & $25.0^{*}$ & $17.4^{* *}$ & $14.6^{* *}$ \\
\hline
\end{tabular}

$$
* \mathbf{P}=\mathbf{0 . 0 5}, * * \mathbf{P}=\mathbf{0 . 0 1}
$$

There was significant treatment mean differences for pre-flowering between treatment 400 Gy and (i) control $(\mathrm{P}=0.003)$ at $95 \%$ confidence level $(8.82-41.72)$ and (ii) 500 Gy $(\mathrm{P}=0.004)$ at $95 \%$ confidence level $(6.61-34.46)$. At flowering significant treatment mean differences existed between treatments $400 \mathrm{~Gy}$ and $600 \mathrm{~Gy}(\mathrm{P}=0.001)$ at $95 \%$ confidence level (20.79-80.37); between treatments $450 \mathrm{~Gy}$ and $600 \mathrm{~Gy}(\mathrm{P}=0.004)$ at $95 \%$ confidence level (16.89 - 85.34); between treatment 600 Gy and the control $(\mathrm{P}-0.015)$ at $95 \%$ confidence level $(-68.87--7.82)$. At post-flowering significant treatment mean difference occurred between treatments 400
Gy and $500 \mathrm{~Gy}(\mathrm{P}=0.000)$ at $95 \%$ confidence level (5.14 - 15.66); between treatments 400 Gy and $600 \mathrm{~Gy}(\mathrm{P}=0.000)$ at $95 \%$ confidence level (14.76-35.21); between treatments 450 Gy and $600(\mathrm{P}-0.004)$ at $95 \%$ confidence level $(6.63-29.12)$; between treatments $500 \mathrm{~Gy}$ and $600 \mathrm{~Gy}(\mathrm{P}=0.005)$ at $95 \%$ confidence level (4.64 - 24.52); between treatment 500 Gy and the control $(\mathrm{P}=0.039)$ at $95 \%$ confidence level $(-11.79--0.32)$; between treatment $600 \mathrm{~Gy}$ and the control $(\mathrm{P}-0.000)$ at $95 \%$ confidence level (-31.11- -10.16).

Results for percentage differences between the control and the other treatments for each of the three different phenological stages are presented in Table 4. 
TABLE 4

Percentage difference between control and the treatments for

the various physiological stages of cowpea.

\begin{tabular}{llll}
\hline \multicolumn{3}{c}{ Percentage difference } \\
\cline { 2 - 4 } Treatment (Gy) & Pre-flowering & Flowering & Post-flowering \\
\hline 400 & $+65.0^{*}$ & +14.2 & +12.8 \\
450 & +36.8 & +14.8 & -9.8 \\
500 & +12.3 & -8.8 & $-18.1 *$ \\
600 & +13.9 & $-44.2^{*}$ & $-61.1^{*}$ \\
$* \mathrm{P}=0.05$ & & &
\end{tabular}

There were different levels of percentage increase in chlorophyll contents at preflowering. Treatment 400 Gy scored a significant increase of 64 percent. above the control. At flowering there was a significant reduction of 44.2 percent of chlorophyll content below the control for $600 \mathrm{~Gy}$. At postflowering there was significant reduction in chlorophyll content for treatments $500 \mathrm{~Gy}$ and 600 Gy.

In the current work there was reduction in mean chlorophyll content at higher gamma doses as compared to the control. This observation is in agreement with the findings of Sinha \& Himanshu (1984) who recorded low concentration of chlorophyll content at high doses of gamma radiations as compared to the control in a study of dolichos bean (Lablab purpureus L.) Gnanamathy \& Dhanavel (2014) in a study using cowpea also recorded reduction in chlorophyll content with increasing dose of gamma radiation.

The percentage increase in chlorophyll content above the control in the current study may be attributed to the fact that the low dose caused an improvement in the photosynthetic capabilities of the irradiated cowpea plants while at high doses the gamma irradiation damaged the photosynthetic pigments which intend reduces the photosynthetic capabilities of the $\mathrm{M}_{1}$ gamma irradiated cowpea plants. This could also be due to reduction of organized pattern of grana and stroma of the thylakoids by the treatments (Alihamonghu et. al., 2011). Sinha \& Himanshu (1984) however also observed that chlorophyll content decreased at lower doses and increased at higher doses in Lablab purpureus L, Vigna unguiculata L. and Phaseolus vulgaris L. There was general reduction in chlorophyll content at postflowering.

\section{Conclusion}

The experiment was conducted to study the effect of gamma irradiation on chlorophyll content in the cowpea for five different doses of gamma rays at three different physiological stages of cowpea. Chlorophyll content was measured in $\mathrm{M}_{2}$ generation. Treatments 400 Gy and 450 Gy gave high chlorophyll content, while treatments 500 Gy and 600 Gy gave lower chlorophyll content. There was a buildup in chlorophyll content from pre-flowering to flowering after which stage there was a drop in the chlorophyll content. The flowering stage demands a lot of photosynthate for zygote formation and development and thus high chlorophyll content. In terms of production increase through gamma irradiation mutation dose 400 Gy and 450 Gy may be appropriate.

\section{Acknowledgements}

The authors are thankful to the Department of Plant and Environmental Biology for providing necessary facilities for carrying out this experiment. We also grateful to staff of the Radiation Technology Centre of the Ghana 
Atomic Energy Commission for irradiation of the cowpea seeds.

\section{References}

Agyeman, K., Berchie, J. N., Osei-Bonsu, I., TetTEH, N. E. \& FordJour, J. K.(2014) Growth and yield performance of improved cowpea. Agricultural Science 2 (4), 44 - 52.

Doumbia, I. Z. (2012) Comparative study of cowpea germplasm from Ghana and Mali using morphological and molecular markers. KNUST, Kumasi.

Gnanamurthy, S. \& Dhanavel, D. (2014) Effect of EMS on induced morphological mutantsand chromosomal variation in Cowpea (Vigna unguiculata (L.) Walp) International Letters of Natural Sciences Online-08-05 ISSN: 2300-9675, 22, $33-43$.

Patil, B. M. \& Rane, G. M. (2015) Gamma radiation induced chlorophyll mutations in cluster bean (Cyamopsis tetragonoloba (L.) Taub) var. NCB-12. Int. J. Allied Pract. Res. Rev. 2, 75 -85 .

Rahimzadeh, P., Hosseini, S. \& Dilmaghani, K. (2011) Effects of UV-A and UV-C radiation on some morphological and physiological parameters in savory (Setureja hortensis L.) Ann. Biol. Res. 2 (5), 164 - 171.
Sinha, S. S. N. \& Himanshu, R, S. (1984) Effect of Gamma Irradiation on Chlorophyll Metabolism in Dolichos, Vigna and Phaseolus species. Cytologia 49, $279-287$.

Swaminathan, M. S., Chopra V, L., Bhaskaran S. (1962). Chromosome aberrations and frequency and spectrum of mutations induced by EMS in barley and wheat. Indian J Genet Plant Breed, 22: 192-2

Swaminathan, M. S., Chopra V, L., Bhaskaran S. (1962). Chromosome aberrations and frequency and spectrum of mutations induced by EMS in barley and wheat. Indian J Genet Plant Breed, 22: 192-2

Swaminathan, M. S., Chopra V, L., Bhaskaran S. (1962). Chromosome aberrations and frequency and spectrum of mutations induced by EMS in barley and wheat. Indian J Genet Plant Breed, 22: 192-207

Swaminathan, M. S., Chopra V, L., Bhaskaran S. (1962) Chromosome aberrations and frequency and spectrum of mutations induced by EMS in barley and wheat. Indian J Genet Plant Breed, 22, $192-207$.

Verma, A. K., Banerji, B. K., Chakrabarty, D. \& DAtTA, S. K. (2010), Studies on M a k h a $\mathrm{n}$ a (Euryale ferox Salisbury). Curr. Sci. 99 (6), $795-800$.

Received 14 Jul 20; revised 13 Jan 21 